\section{The Long-Term Effect of an Outpatient Intervention Program with a Behavioral Therapy Approach in Patients with Chronic Back or Neck Pain with a Focus on Psychosocial Aspects}

\section{Peter Machacek, Florian Wepner, Joerg Holzapfel, Julia Hahne $^{*}$ and Martin Friedrich}

Orthopedic Hospital, CEOPS (Center of Excellence for Orthopedic Pain Management Speising), Vienna, Austria

\begin{abstract}
Objective: Success of outpatient intervention programs consisting of physiotherapy in patients with non-specific chronic back or neck pain has not been conclusively proven. Greater attention to psychosocial factors may improve outcome. We investigated whether an outpatient intervention program with a behavioral therapy approach would exert a long-term effect on non-specific chronic back or neck pain specifically on patients with pronounced fear avoidance behavior and/or with psychosocial limitations.

Design: Prospective, randomized controlled trial.

Subject/Patients: 121 patients were assigned to either the intervention or control group. The intervention group received a program of 9 units physiotherapy and 2 units occupational therapy, conducted with a behavioral therapy approach. The control group received standard care.

Methods: Efficacy of treatment was evaluated after 6 and 58 weeks by measurements of pain, quantity of painkillers, sick leave days, disability, health related quality of life, and fear avoidance.

Results: The intervention group consumed significantly less painkillers after 58 weeks and showed reduced fear avoidance behavior after 6 weeks. No significant associations were observed between patients with high or low fear avoidance and pain severity, days of sick leave, health related quality of life, or disability.
\end{abstract}

*Corresponding author: Julia Hahne, Center of Excellence for Orthopedic Pain Management Speising, Orthopedic Hospital Vienna, Speisinger 109, 1130 Vienna, Austria, Tel: +43 180182 1583; E-mail: julia.hahne@oss.at

Citation: Machacek P, Wepner M, Holzapfel J, Hahne J, Friedrich M (2015). The Long-Term Effect of an Outpatient Intervention Program with a Behavioral Therapy Approach in Patients with Chronic Back or Neck Pain with a Focus on Psychosocial Aspects. J Orthop Res Physiother 1: 014

Received: August 13, 2015; Accepted: October 05, 2015; Published: October 19, 2015
Conclusion: An outpatient intervention program is not sufficiently effective in the long term when administered without due regard to accompanying psychosocial factors.

Keywords: Behavioral therapy approach; Chronic pain; Cognition therapy; Fear avoidance beliefs; Health-related quality of life; Multidisciplinary rehabilitation; Non-specific neck pain; Occupational therapy; Outpatient intervention program; Physical therapy; Physiotherapy; Psychosocial factors

\section{Introduction}

The long-term success of outpatient intervention programs based on individual and group physiotherapy with or without a behavioral therapy approach in patients with non-specific chronic Pain in the Back or neck (cBP) is controversially discussed [1-3]. Such programs appear to be helpful in the short or mid-term [4,5], but the results are usually not retained in the long term-i.e., over a period of 6 to 12 months [6,7]. As regards sustained effects, short-term programs with a behavioral therapy approach are not markedly superior to those without behavioral therapy approach even in patients with neck pain [8]. In general the effect of exercise therapy in treating low back pain differs a lot. A Cochrane review of Hayden et al., [9] shows some evidence for a subacute low back pain population, but poor outcome with acute patients. The best results are pointed out at chronic low back pain patients, which on the other hand had the longest period of treatment. It is remarkable that in the Cochrane review of Henschke [6] the behavioral therapy for low back pain is more effective than usual care, but there was no specific type of behavioral therapy to be the most effective. Howsoever cognitive behavioral treatments do have a positive influence and effect on pain syndromes of the low back. In the Cochrane Review of Monticone [10] the clinical meaningfulness of cognitive behavioral treatment for chronic neck pain is doubted. Still there was low quality evidence shown that cognitive behavioral treatment was better than no treatment for improving pain, disability, and quality of life. The best effect was shown at patients with acute neck pain.

Psychosocial risk factors are described in the literature to have the potential to prolong disability and delay the return to the work place in patients with back or neck pain $[11,12]$. These risk factors include fears about pain or injury-especially when associated with avoidance behavior, unhelpful beliefs about recovery, and distress affect (e.g., despondency and anxiety) $[13,14]$.

A further problem is that the current literature only offers studies which are not clearly comparable due to their different composition of control groups and the varying length and structure of the programs [15-17]. At least the studies of Lamb et al., [18] and O'Sullivan et al., [19] are reproducible regarding study designs and therapy measurements. However, the question arises as to whether such complex and specific programs can be performed by outside specialized centers, and whether simple programs with careful selection of patients would yield results of similar good quality.

From the literature presented above, the following research questionsarise: Can a standardized physiotherapy program with occupational therapy elements and a behavioral therapy approach be 
effective for chronic back and neck pain patients? Do these patients react differently depending on their level of fear avoidance behavior?

\section{Method}

\section{Study design and approach}

The approach we used in the present study was to let patients with cBP undergo an outpatient program focusing on behavioral therapy and compare this patient group with a control group of patients following treatment as usual which includes the handout of either the back or the neck book and a consultation of the general practitioner who would take over the treatment. Exercises were selected in a manner that they could be easily comprehended and performed by the patients as well as reproduced for other therapists. The success of both programs was evaluated for a period of one year. Special attention was given to psychosocial aspects. In this study we observed how persons with marked fear avoidance behavior and those with marked subjective limitations due to disease or psychosocial limitations reacted to the interventions as compared to persons who were less limited in these aspects. The purpose was to determine whether simple and standardized ascertainment of psychosocial factors before the start of an intervention program would affect the outcome of interventions in patients with neck or back pain.

The main hypothesis of our research project was that a standardized training program would have effects on pain levels (measured with visual analog scales), compared with a control group that only received usual care. Secondary hypotheses dealt with the intake of pain killers, number of sick leave days, disability, health related quality of life and fear avoidance behavior.

\section{Participants and recruitment}

The desired target group consisted of patients who had experienced non-specific spinal symptoms of moderate or severe intensity in the preceding six months.

\section{Inclusion criteria}

Men from 18 to 55, women from 18 to 50 years of age who had been on sick leave for a minimum of 4 and a maximum of 22 days during the preceding 12 months because of non-specific spinal symptoms in the back or neck were included into the study. The patients had to be working at the start of the study. The different ages result from heterogeneous retirement rules in our country.

\section{Exclusion criteria}

Excluded were patients with specific causes of spinal symptoms: after spinal surgery, known vertebral body fractures, disk prolapse with motor deficits or other radicular lesions, tumor, osteomyelitis, spondylodiscitis, rheumatic disease, osteoporosis. Retired persons, those in the process of being screened for retirement, unemployed persons, pregnant women or persons on maternity leave were excluded as well. Other exclusion reasons were planned surgery during the phase of intervention and inability to participate in the intervention program for other reasons (physical, psychological, linguistic or organizational).

\section{Recruitment}

The ethics committee of the city of Vienna issued its consent to the exceution of this study. Patients were recruited on the basis of sick leave data at the local health insurance agencies. Data protection regulations were taken into account. Persons with suitable inclusion criteria received a letter from the the local health insurance agency. The study was introduced in the letter and patients were offered to participate in the intervention program. After informing the patients, obtaining their verbal consent, and a preliminary screening procedure on the telephone, suitable patients were invited for the screening investigation. At this investigation the patients were examined for in- and exlusion criteria by an experienced orthopedic at the study site, an orthopedic hospital. Patients were then recruited for the study after renewed evaluation of inclusion criteria and after they had been informed and had signed the consent form. The patients were then randomized to the Intervention Group (IG) or the Control Group (CG). Randomization was performed by an independent person who was not involved in the study between January 2007 and December 2009.

\section{Procedures}

Members of both groups were handed out the "back book" or the "neck book" after they had been included in the study. Patients were advised to study the booklets at home, but no joint review was held. One of the reasons for handing out the booklet was to enhance the control group's motivation to participate in the follow-up investigation. Developed by Roland et al., the booklets inform the readers about the non-hazardous nature of non-specific back and neck symptoms. They also provide information about proper management of back or neck pain [20,21]. The "back book" was available in German language, translated by Nilges et al., [22]. As the "neck book" was only available in its original form, it was first translated into German, then translated back into English by an independent person and, after obtaining the consent of the authors and the publisher (The Stationery Office, St. Crispins, Duke Street, Norwich NR 3 1PD) as well as a graphic review, it was finally duplicated in German language [23]. Members of the CG were referred to their general practitioner for further care. There was no tracking of the amount of exercise practicing.

Members of the IG received 9 units of Physiotherapy (PT) and 2 units of Occupational Therapy (OT), each lasting one hour. Every patient of the IG was trained to perform either a neck or back intervention program specifically suited to his/her needs. Prior to the start of the 6-week training program, each test person received an individual introduction of 1 hour by a physiotherapist, which was adjusted to the specific needs (neck or back). The single session was conducted by one of three experienced physiotherapists (with mean work experience of 6 years). After this training the patients completed 8 group training units with a maximum number of 8 participants, over a maximum period of six weeks. The patients were not permitted to miss more than 2 units of the PT sessions.

The physiotherapeutic intervention program was designed as circuit training and was supervised alternately by one of the physiotherapists, who adhered to standardized care guidelines. The aims in this part were strengthening of the muscles of the trunk and cervical spine as well as transporting the idea of joy in physical activity and active dealing with pain. This was primarily achieved by activating deep stabilizers of the lumbar spine and deep flexors of the cervical spine in combination with the superficial abdominal muscles and muscles of the spine and shoulder girdle [24]. Further emphasis was put on training of coordination by improving the sense of balance. Coordination abilities were trained by means of balance exercises. The exercises were designed to be performed by persons of all proficiency levels. The exercises could also be performed at home 
with minimal equipment (a Theraband ${ }^{\circledast}$ was handed out to each patient). For each exercise, the level of difficulty could be increased by altering the motion, increasing the number of repetitions or weights. This was recorded by the patients on a special protocol for every training unit and every exercise. All participants received the intervention program in writing, together with pictures and explanations of the drills. This was also done for the purpose of documentation. Each patient was free to select the order of exercises, but had to complete all exercises in one training unit. Attention was given to the execution quality of the exercises, which was checked on an ongoing basis. The patients were instructed to perform the exercises regularly at home.

During the entire intervention phase, behavioural therapy measures based on those proposed by Butler and Mosley [25] were performed. Patients were advised not to focus on the pain and to continue daily activities without restrictions. They were educated that physical activity does not lead to tissue damage and, on the other side, inactivity can support chronic pain.

Specifically, associations between fear avoidance behavior and chronic back pain were investigated, and motivational aspects identified.

\begin{tabular}{|c|c|c|}
\hline & Lumbar spine training & Cervical spine training \\
\hline $\begin{array}{l}\text { Prior to } \\
\text { each } \\
\text { exercise }\end{array}$ & $\begin{array}{l}\text { Activation of M. transversus } \\
\text { abdominis obtaining a neutral } \\
\text { position of the lumbar spine }\end{array}$ & $\begin{array}{c}\text { Activation of the deep flexors } \\
\text { of the neck obtaining a neu- } \\
\text { tral position of the cervical } \\
\text { spine }\end{array}$ \\
\hline \multicolumn{3}{|c|}{ Exercise } \\
\hline 1 & Squats with barbells & $\begin{array}{l}\text { Push-ups against the wall/on } \\
\text { the floor }\end{array}$ \\
\hline 2 & $\begin{array}{l}\text { Cable winch, squat position, } \\
\text { extension of the shoulder from } \\
\text { flexed position }\end{array}$ & $\begin{array}{l}\text { Sedentary position, pulling } \\
\text { latissimus towards chest }\end{array}$ \\
\hline 3 & $\begin{array}{l}\text { Training of abdominal muscles, } \\
\text { extension/flexion in horizontal } \\
\text { position (monitoring of position } \\
\text { of the lumbar spine with blood } \\
\text { pressure cuff) }\end{array}$ & $\begin{array}{l}\text { Training of the deep flexors of } \\
\text { the neck in horizontal position } \\
\text { using a blood pressure cuff }\end{array}$ \\
\hline 4 & $\begin{array}{l}\text { Small rotations of the thoracal } \\
\text { spine in squat position }\end{array}$ & Military press with dumbbells \\
\hline 5 & $\begin{array}{l}\text { Resting on lower arm, leg } \\
\text { exercises }\end{array}$ & Shrugs with dumbbells \\
\hline 6 & $\begin{array}{l}\text { Standing position, extension/flex- } \\
\text { ion against resistance provided by } \\
\text { the Thera band }{ }^{\circledR}\end{array}$ & $\begin{array}{l}\text { Rotations of the thoracal } \\
\text { spine in sedentary position }\end{array}$ \\
\hline 7 & $\begin{array}{l}\text { Training of balance-coordination } \\
\text { with a spinner }\end{array}$ & $\begin{array}{l}\text { Stabilisation of the cervical } \\
\text { spine using a Thera band }{ }^{\circledR} \\
\text { wrapped around the head }\end{array}$ \\
\hline 8 & & $\begin{array}{l}\text { Training of balance-coordina- } \\
\text { tion with spinner }\end{array}$ \\
\hline
\end{tabular}

In the two units of occupational therapy the patients were divided into a group that primarily performed sedentary activities or a second group that primarily performed heavy physical work depending on their profession. The aims were to encourage the knowledge about ergonomics in everyday - life and to strengthen physical perception. The goal was to offer patients an alternative way to handle their pain. In the first unit, a lecture was given to the participants on basic knowledge regarding ergonomics in everyday-life followed by a hands-on training of relevant situations (e.g., lifting with activated basic tension). The second unit (build-up session) included an analysis of the individual work-situation of the participants in small groups, and helped to implement possibilities for optimizing their general working conditions.

During the sessions, compliance with the therapy was observed by the PTs and patients were encouraged to give feedback about their training progress.

\section{Outcome Measurements}

The data were evaluated on site after the screening investigation (time point 1) and after completing the intervention program (6 weeks, time point 2) as well as after 58 weeks (time point 3 ) by regular mail.

To evaluate the main hypothesis, current pain and mean pain during the preceding week and the preceding 3 months were determined on a Visual Analog Scale (VAS; 0-100, lower scores indicate less severe pain).

The Oswestry Disability Index (ODI, the higher the values, the higher the limitation of activity; scale 0-100) [26,27] was used to measure functional impairment. To evaluate health related quality of life, we used the 36-item short form health survey (SF-36; scales 0-100, Lower scores indicate poorer mental and physical quality of life) [28]. Anxiety, insecurity in social contacts and compulsiveness were registered on the Brief Symptoms Inventory (BSI), which is an abridged version of SCL-90-R [29,30]. The BSI addresses subjective experience of impairment based on a list of symptoms that are partly physical and partly psychological in a time frame of seven days. Thus, it is not a measurement of stable (personality) traits.

At time point 1 and 3, the number of (self-reported) days of sick leave due to pain during the preceding twelve months and the number of painkillers taken per day were inquired. Fear avoidance behavior was determined by means of the Fear Avoidance Beliefs Questionnaire (FABQ; scale 0-66; lower scores indicate lower fear-avoidance beliefs) [31]. For further evaluation, patients demonstrating strong Fear Avoidance Behavior (FABQ cut-off value $>29$ ) were compared to those with milder Fear Avoidance Behavior (FABQ cut-off value $<28$ ).

\section{Statistical Analysis}

Prior to study onset, the sample size was estimated resting upon the following parameters: The alpha error was set to $5 \%$, the beta error to $80 \%$. The threshold for minimal clinically important difference between the test groups for the main outcome variable "sick leave" was set at 5 days. As a result, the required sample size was estimated to be 52 patients per treatment group.

In the first step we assessed whether and to what extent study drop-outs differed from study participants in terms of selected basic variables. Concerning the variables of gender, group (IG vs. CG; occupational therapy group, physiotherapy group), training and marital status, this question was investigated by means of chi-square tests. Regarding age, days of sick leave before inclusion in the study, VAS, and the number of years since the onset of pain, mean value comparisons were performed by means of t-tests for independent random samples.

Statistical evaluation of the primary hypothesis (change in the number of days of sick leave during one year after therapy at least in one of the groups) was performed by means of two-fold variance analysis for repeated measurements. A prerequisite for this test 
procedure was homogeneity of variances in the individual subgroups. These were tested by means of Levine's test. Normal distribution of values within a group was checked visually on histograms. Secondary hypotheses (impact of the therapy on the severity of pain, health-related quality of life, disease-related limitations, fear avoidance behavior) were also investigated by means of variance analyses of repeated measurements. Tests for violation of prerequisites were checked by visual control of histograms. Significances between the individual time points were determined by means of contrast analysis. The limit for the significance of a contrast was set to 0.05 .

BSI scale values were transformed into t-values, which express associations with the normal population. All persons who had $\mathrm{t}$-values $<60$ were assigned to an "affected" group for each sub-scale. The term "affected" in this context did not necessarily refer to a patient with noticeable clinical features, but that the symptoms were more severe than those in the normal population. For further evaluation, changes in the individual affected groups were determined in relation to VAS, ODI, FABQ and the SF-36.

\section{Results}

One hundred and twenty-one persons fulfilled the inclusion criteria for this study. Of these, $53 \%$ were in the IG and $47 \%$ in the CG. At time point 2, data could be obtained for $93 \%$ of the original population (55\% in IG and 45\% in CG) (Figure 1). At time point 3, 84\% of the initially investigated patients completed the questionnaires and examinations (drop-out rate of 15\%).

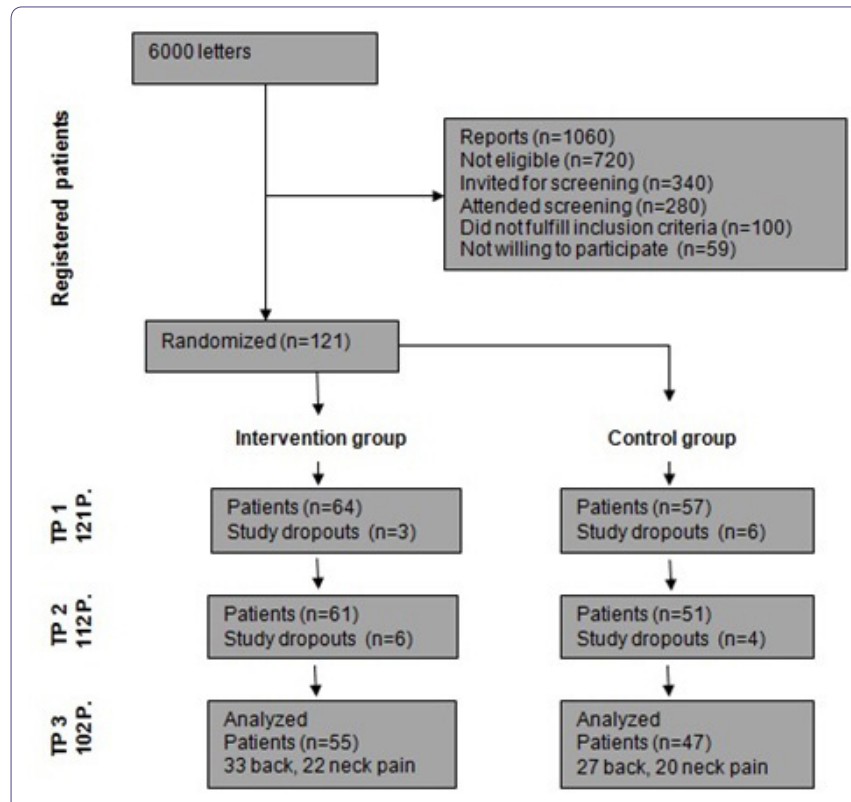

Figure 1: Flow chart depicting recruitment, randomization and retention of participants.

The two groups did not differ significantly in terms of most baseline data at the onset of the study. However, in the mean VAS of the preceding week the CG had significantly higher baseline values (Table 2).

Study dropouts differed significantly from those who remained in the study at time point 1 only with reference to the VAS time frame of 1 week $(\mathrm{p}=0.001)$. Study dropouts had less pain (VAS $35 \pm 2.5$

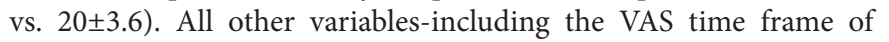
3 months-revealed no significant differences.

\begin{tabular}{|c|c|c|c|}
\hline & Training Group & Control Group & p \\
\hline Age [mean (SD)] & $39.13(6.955)$ & 38.55 (7.942) & 0.698 \\
\hline $\begin{array}{l}\text { Gender \% } \\
\text { Male } \\
\text { Female }\end{array}$ & $\begin{array}{l}38.2 \\
61.8\end{array}$ & $\begin{array}{l}29.8 \\
70.2\end{array}$ & 0.373 \\
\hline BMI [mean (SD)] & $25.62(4.135)$ & $26.02(5.613)$ & 0.689 \\
\hline Days of sick leave [mean (SD)] & $10.91(7.326)$ & $11.23(7.529)$ & 0.832 \\
\hline $\begin{array}{c}\text { Occupation (\%) } \\
\text { Laborer } \\
\text { Employee } \\
\text { Civil servant } \\
\text { Unemployed }\end{array}$ & $\begin{array}{c}18.2 \\
78.2 \\
3.6 \\
0.0\end{array}$ & $\begin{array}{c}17.0 \\
78.7 \\
2.2 \\
2.1\end{array}$ & 0.397 \\
\hline $\begin{array}{c}\text { Extent of employment (\%) } \\
\text { Part-time } \\
\text { Full-time }\end{array}$ & $\begin{array}{c}9.1 \\
90.9\end{array}$ & $\begin{array}{l}12.8 \\
87.2\end{array}$ & 0.551 \\
\hline $\begin{array}{l}\text { Marital status (\%) } \\
\text { Living alone } \\
\text { Married/Living-in } \\
\text { Divorced }\end{array}$ & $\begin{array}{l}18.2 \\
69.1 \\
12.8\end{array}$ & $\begin{array}{l}21.3 \\
68.1 \\
10.6\end{array}$ & 0.895 \\
\hline $\begin{array}{l}\text { Education }(\%) \\
\text { Primary school } \\
\text { Vocational training } \\
\text { High school } \\
\text { University }\end{array}$ & $\begin{array}{c}5.5 \\
40.0 \\
38.2 \\
16.4\end{array}$ & $\begin{array}{l}12.8 \\
46.8 \\
27.7 \\
12.8\end{array}$ & 0.412 \\
\hline Pain intensity 3 month [mean (SD)] & $36.00(22.558)$ & $40.80(25.272)$ & 0.320 \\
\hline Pain intensity 1 week [mean (SD)] & $34.38(23.006)$ & $44.02(23.719)$ & 0.053 \\
\hline $\mathrm{FABQ}$ [mean (SD)] & $29.30(16.145)$ & $29.34(14.717)$ & 0.990 \\
\hline $\begin{array}{l}\text { SF36 [mean (SD)] } \\
\text { Physical scale } \\
\text { Mental scale }\end{array}$ & $\begin{array}{l}48.60(7.339) \\
51.55(8.007)\end{array}$ & $\begin{array}{l}45.74(7.483) \\
49.29(9.486)\end{array}$ & $\begin{array}{l}0.057 \\
0.199\end{array}$ \\
\hline $\begin{array}{l}\text { Number of years since the onset of } \\
\text { pain [mean (SD)] }\end{array}$ & $7.85(6.166)$ & $6.91(5.614)$ & 0.444 \\
\hline
\end{tabular}

Evaluation of the exercise protocols of members of the training group after the last group physiotherapy session revealed a significant improvement in the number of repetitions and an increase of training weights over time in regard of all exercises.

VAS dropped at time point 2 in both groups. After one year the CG revealed a further drop in VAS while the IG showed a slight increase (Table 3). The results, however, were not significant - neither over time nor between groups.

\begin{tabular}{|c|c|c|c|}
\hline Group & Mean & $\begin{array}{c}\text { Standard } \\
\text { Deviation }\end{array}$ & N \\
\hline VAS 7 days, TP 1 Training group & 28.25 & 23.488 & 53 \\
Control group & 40.33 & 24.812 & 43 \\
Total & 33.66 & 24.711 & 96 \\
\hline VAS 7 days, TP 2 Training group & 23.30 & 23.240 & 53 \\
Control group & 35.33 & 25.084 & 43 \\
Total & 28.69 & 24.697 & 96 \\
\hline VAS 7 days, TP 3 Training group & 26.91 & 26.782 & 53 \\
Control group & 29.00 & 26.303 & 43 \\
Total & 27.84 & 26.450 & 96 \\
\hline
\end{tabular}

Table 3: Severity of pain (VAS) at the three Time Points (TP).

At time point 3 the IG showed a significantly lower intake of painkillers compared to time point 1 ( $\chi^{2}$ test, $p=0.002$ ). The intake of painkillers was reduced in the CG as well, but the reduction between time point 1 and time point 3 was not statistically significant $\left(\chi^{2}\right.$ test, $\mathrm{p}=0.067$ ).

At time point 1 and 3 the two groups did not differ significantly with regard to the intake of painkillers (time point $1: \chi^{2}$ test, $p=0.801$; time point 3: $\chi^{2}$ test, $\mathrm{p}=0.765$ ). 
Regarding ODI, a significant time effect was noted in both groups at time point $2(\mathrm{p}=0.020)$, but no significant group effect was noted (Figure 2).

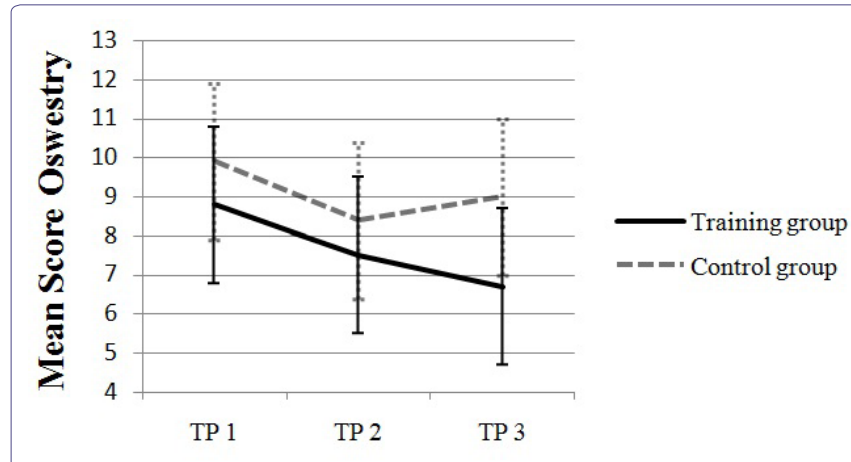

Figure 2: Mean Scores and standard deviation of the Oswestry disability index (extract from the 0-100 scale), TP=time point.

For SF 36, neither the physical nor the mental total score revealed a significant group or time effect at the three time points.

As regards the number of (self-reported) days of sick leave, significantly fewer days were registered for both groups over time (mean sick leave days at time point one: 10.6; at time point two: 5.29 days; $\mathrm{p}=0.000)$. No significant differences between the two groups were noted $(\mathrm{p}=0.965)$.

As regards the above mentioned data, no significant differences were observed between patients with neck pain as well as those with back pain.

With regard to FABQ, strong but non-significant group effects were noted after the intervention (time point 2). Patients in the behavior therapy-oriented group had markedly better values than the CG. At time point 3 these differences were largely nullified (Figure 3).

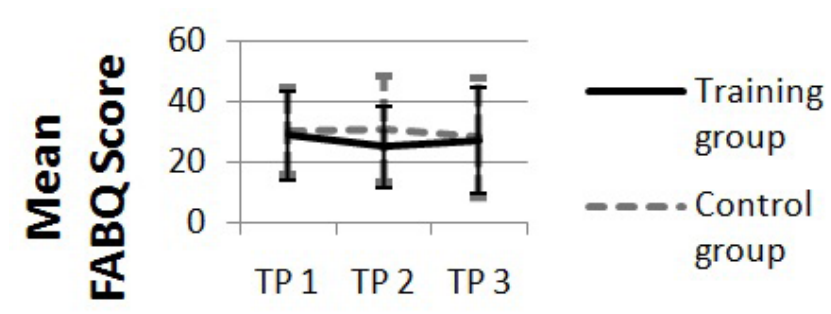

Figure 3: Mean Scores and standard deviation FABQ (Scale: 0-66), TP=time point.

After the groups had been divided into persons who demonstrated mild Fear Avoidance Behavior (FABQ score 28 or lower; $52 \%$ of the random sample) and those with marked Fear Avoidance Behavior (FABQ score 29 or higher; $48 \%$ of the random sample) at time point 1 , in the IG the fear avoidance behavior of persons with a high FABQ score was markedly improved in the short term. Here a significant drop in values $(\mathrm{p}=0.015)$ was noted compared to time point 2. However, the same group experienced a slight increase in values after one year (Figure 4), but these values did not differ significantly from those at time point 1 . Persons with a low FABQ score at time point 1 generally demonstrated less change in their fear avoidance behavior. In the CG, patients with high values at time point 1 did not demonstrate significantly less pronounced fear avoidance behavior at time points 2 and 3 .

In the investigated population we observed a significant $(\mathrm{r}=0.338$, $\mathrm{p}=0.001$ ) correlation between FABQ scores and the severity of pain.

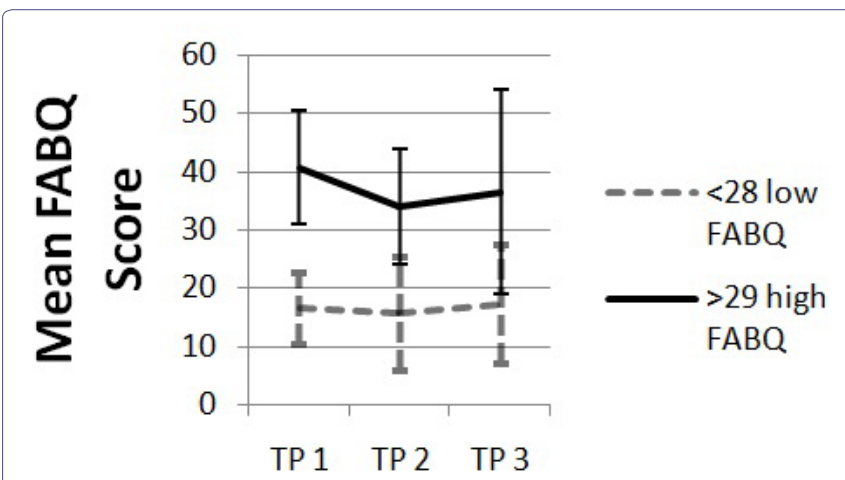

Figure 4: FABQ-behavior of persons with low and high baseline values (Scale: 0-66), mean scores and standard deviation, TP=time point.

In other words, persons with high FABQ scores reported more severe pain at time point 1 in our population.

However, no significant associations were observed between patients with a high and a low FABQ score, and a change in the intensity of pain, the number of days of sick leave, SF-36, or the ODI, independent of group membership.

Evaluation of the BSI revealed significant results only in those patients who were remarkable in terms of somatization. Thus, a significantly stronger resurgence on the VAS scale (time frame of one week) and the FABQ was registered between time point 2 and time point 3, independent of group membership (IG or CG).

\section{Discussion}

In general it was found that an outpatient intervention program of this type for patients with chronic symptoms of the spine is not sufficiently effective in the long term when administered without due regard to accompanying psychosocial factors. Thus, for selected patients with chronic symptoms one should design and offer, on a widespread basis, the option of intensive interdisciplinary regimens by way of functional restoration programs that include individual in-patient and out-patient treatment [32,33]. According to current scientific knowledge such programs should include at least 100 hours of therapy [34].

The only significant difference between the groups after one year was a reduction in the intake of painkillers in the IG. As regards pain, after one year no major differences were noted-neither between groups nor over time. Of course this lack of a significant difference may have also been due to the lower intake of painkillers in the intervention group after one year, but this appears to be unlikely in view of the absence of significant group differences in FABQ, ODI or SF-36 scores. The number of days of sick leave was also reduced in both groups, with no significant difference between groups.

As regards fear avoidance behavior, especially patients with high FABQ scores demonstrated a significant improvement immediately after the intervention as compared to the CG. In the former group the program appears to have been quite successful initially, but the values could not be retained over a period of one year.

Especially among patients who tended to somatize their symptoms we noted an increase in fear avoidance behavior as well as a rapid return of VAS scores to near-baseline values after the intervention program. Thus, a refresher program and a repetition of behavioral therapy measures would be meaningful. 
It would also be useful to administer such behavioral-therapy-oriented programs primarily to patients with marked fear avoidance behavior and/or additional psychological difficulties. Thus, when dealing with patients with chronic back pain, attention should be focused on psychosocial risk factors and the treatment should be modified accordingly. The contradictory statements reported in the published literature regarding the efficacy of fitness programs with or without behavior therapy, such as those mentioned in a review performed by van Middelkoop et al., [1] may result in too little attention being given to the above mentioned factors at the start of the reported programs. Usually all patients are treated the same way, regardless of these factors. However, psychosocial factors such as catastrophizing, fear avoidance, somatization, depression and distress cause a two-fold increase in the risk of chronic back pain [34]. As early as in the 1990's it was found that fear avoidance behavior is probably the most important prognostic factor in the process of chronification, and that it would be quite meaningful to inform patients appropriately as early as possible [35-37].

Careful screening of patients, based on a biopsychosocial approach, would therefore be meaningful. For such an evaluation we have various types of high-quality screening instruments and questionnaires [38]. However, we have achieved no international consensus which of the questionnaires should be used. This aspect could also be addressed in future research such as in the study protocol of O'Keeffe et al., [39].

Finally, we would like to point to the limitations of our study: All patients included in the study had been experiencing pain for a long time (on average about 7 years), which might be a possible reason for the poor sustained effect of the program. Participation in the program was voluntary. Persons who received written requests had to report to us by telephone. It may therefore be assumed that a large number of patients with pre-existing severe symptoms were interested in the program. Study dropouts had significantly less pain at time point 1 than those who remained in the study. This might be an indication of the fact that these patients rated the effort involved in the study too high in relation to their rather mild symptoms. The CG had a significantly higher VAS score (time frame of 7 days) at time point 1. A higher VAS in the IG possibly would have resulted in stronger differences in the results. After the first investigation the neck or back book was handed out to the CG as well. The back book has been found to exert a positive effect in patients with back pain [40]. This would explain the response of the CG in terms of a reduction on the ODI at time point 2. However, we had expected the intervention program to significantly exceed the effect of the neck or back book alone. Members of the CG received less treatment because the program was not conducted here. But the patients of this group might have been additionally motivated by the investigation and the information they received and might have requested additional extern treatment. This could have been the reason for the observed improvement in the CG and may have reduced group differences as well. Possibly, in future studies one should give more attention to the evaluation of so-called "treatment as usual" [41]. The exercises learned by the IG could be performed independently at home. However, the significant increase in the number of repetitions, the increase in training weights, and the change in execution does lead one to suspect that the participants performed an independent short-term exercise program at home, but we did not determine whether the exercises were performed after one year as well. Besides, in the case of the neck and spine book we did not check whether the instructions were actually read and followed by the study participants.
Furthermore, it was not possible to separate effects of exercise vs. behavioral therapy.

Future investigations will show whether more successful therapy options can be designed for patients with acute or subacute back pain while taking psychosocial factors into account when administering outpatient therapy programs, and whether chronic pain can thus be largely prevented. For patients with chronic back pain only intensive interdisciplinary programs with both in-patient and out-patient treatment modules can be helpful for long term view.

\section{References}

1. van Middelkoop M, Rubinstein SM, Kuijpers T, Verhagen AP, Ostelo R, et al (2011) A systematic review on the effectiveness of physical and rehabilitation interventions for chronic non-specific low back pain. Eur Spine J 20: 19-39.

2. Johnson RE, Jones GT, Wiles NJ, Chaddock C, Potter RG, et al. (2007) Active exercise, education, and cognitive behavioral therapy for persistent disabling low back pain: a randomized controlled trial. Spine (Phila Pa 1976) 32: 1578-1585.

3. Momsen AM, Rasmussen JO, Nielsen CV, Iversen MD, Lund H (2012) Multidisciplinary team care in rehabilitation: an overview of reviews. J Rehabil Med 44: 901-912.

4. Gustavsson C, Denison E, von Koch L (2010) Self-management of persistent neck pain: a randomized controlled trial of a multi-component group intervention in primary health care. Eur J Pain 14: 630

5. Leo Ng, Cañeiro JP, Campbell A, Smith A, Burnett A, et al. (2015) Cognitive functional approach to manage low back pain in male adolescent rowers: a randomized controlled trial. Br J Sports Med 49: 1125-1131.

6. Henschke N, Ostelo RW, van Tulder MW, Vlaeyen JW, Morley S, et al. (2010) Behavioural treatment for chronic low-back pain. Cochrane Database Syst Rev: CD002014.

7. Vibe Fersum K, O'Sullivan P, Skouen JS, Smith A, Kvale A (2013) Efficacy of classification-based cognitive functional therapy in patients with non-specific chronic low back pain: a randomized controlled trial. Eur J Pain 17: 916-928.

8. Haines T, Gross A, Goldsmith CH, Perry L (2008) Patient education for neck pain with or without radiculopathy. Cochrane Database Syst Rev: CD005106.

9. Hayden JA, van Tulder MW, Malmivaara A, Koes BW (2005) Exercise therapy for treatment of non-specific low back pain. Cochrane Database Syst Rev: CD000335.

10. Monticone M, Ambrosini E, Cedraschi C, Rocca B, Fiorentini R, et al. (2015) Cognitive-behavioural treatment for subacute and chronic neck pain: A Cochrane Review. Spine 40: 1495-1504.

11. Monticone M, Baiardi P, Vanti C, Ferrari S, Nava T, et al. (2012) Chronic neck pain and treatment of cognitive and behavioural factors: results of a randomised controlled clinical trial. Eur Spine J 21: 1558-1566.

12. Sveinsdottir V, Eriksen HR, Reme SE (2012) Assessing the role of cognitive behavioral therapy in the management of chronic nonspecific back pain. J Pain Res 5: 371-380.

13. Nicholas MK, Linton SJ, Watson PJ, Main CJ, "Decade of the Flags" Working Group (2011) Early identification and management of psychological risk factors ("yellow flags") in patients with low back pain: a reappraisal. Phys Ther 91: 737-753

14. Leeuw M, Goossens ME, Linton SJ, Crombez G, Boersma K, et al. (2007) The fear-avoidance model of musculoskeletal pain: current state of scientific evidence. J Behav Med 30: 77-94.

15. Lansinger B, Larsson E, Persson LC, Carlsson JY (2007) Qigong and exercise therapy in patients with long-term neck pain: a prospective randomized trial. Spine (Phila Pa 1976) 32: 2415-2422.

16. Hudson JS, Ryan CG (2010) Multimodal group rehabilitation compared to usual care for patients with chronic neck pain: a pilot study. Man Ther 15: 552-556. 
17. Garcia AN, Costa Lda C, da Silva TM, Gondo FL, Cyrillo FN, et al. (2013) Effectiveness of back school versus McKenzie exercises in patients with chronic nonspecific low back pain: a randomized controlled trial. Phys Ther 93: 729-747.

18. Lamb SE, Hansen Z, Lall R, Castelnuovo E, Withers EJ, et al. (2010) Group cognitive behavioural treatment for low-back pain in primary care: a randomised controlled trial and cost-effectiveness analysis. Lancet 13: 916-923.

19. O'Sullivan K, Dankaerts W, O'Sullivan L, O'Sullivan PB (2015) Cognitive functional therapy for disabling nonspecific chronic low back pain: Multiple case-cohort study. Phys Ther.

20. Roland M, Waddell G, Klaber-Moffett J, Burton K, Main C (2002) The Back Book. In: The best way to deal with back pain. Get Back Active. (2ndedn), The Stationary Office, St. Crispins, Duke Street, Norwich, England.

21. Roland M, Waddell G, Klaber-Moffett J, Burton K, Main C, et al. (2004) The Neck Book. In: The best way to deal with neck pain. Based on the latest research, The Stationery Office, St. Crispins, Duke Street, Norwich, England.

22. Nilges P, Roland M, Waddell G, Klaber Mofett J, Burton K, et al. (2000) Das Rücken-Buch: aktuelle Ratschläge: Was Sie selbst für Ihren Rücken tun können. DRK Schmerz-Zentrum Mainz, Germany.

23. Friedrich M, Wepner F (2006) Das Nackenbuch. Der beste Umgang mit Nackenschmerzen. Basierend auf dem neuesten Stand der Wissenschaft und Medizin. Vienna: CEOPS, Copyright: The Stationery Office, St. Crispins, Duke Street, Norwich NR 3 1PD.

24. Hides JA, Jull GA, Richardson CA (2001) Long-term effects of specific stabilizing exercises for first-episode low back pain. Spine (Phila Pa 1976) 26 243-248.

25. Butler D, Moseley L (2005) Schmerzen verstehen. Springer-Verlag Berlin Heidelberg, Germany.

26. Mannion AF, Junge A, Fairbank JC, Dvorak J, Grob D (2006) Development of a German version of the Oswestry Disability Index. Part 1: cross-cultural adaptation, reliability, and validity. Eur Spine J 15: 55-65

27. Mannion AF, Junge A, Grob D, Dvorak J, Fairbank JC (2006) Development of a German version of the Oswestry Disability Index. Part 2: sensitivity to change after spinal surgery. Eur Spine J 15: 66-73.

28. Bullinger M, Kirchberger I (1998) Der SF-36 Fragebogen zum Gesundheitszustand. Hogrefe publishing, Göttingen, Germany.

29. Franke GH (1995) Die Symptom-Checkliste von Derogatis: Manual. [SCL90-R]; deutsche Version. Beltz Test, Göttingen, Germany.
30. Franke GH (2000) Brief Symptom Inventory von L.R. Derogatis; BSI; (Kurzform der SCL-90-R); deutsche Version. Beltz Test, Göttingen, Germany.

31. Pfingsten M, Kröner-Herwig B, Leibing E, Kronshage U, Hildebrandt J (2000) Validation of the German version of the Fear-Avoidance Beliefs Questionnaire (FABQ). Eur J Pain 4: 259-266.

32. Airaksinen O, Brox JI, Cedraschi C, Hildebrandt J, Klaber-Moffett J, et al. (2006) Chapter 4. European guidelines for the management of chronic nonspecific low back pain. Eur Spine J 15: 192-300.

33. Chou R, Loeser JD, Owens DK, Rosenquist RW, Atlas SJ, et al. (2009) Interventional therapies, surgery, and interdisciplinary rehabilitation for low back pain: an evidence-based clinical practice guideline from the American Pain Society. Spine (Phila Pa 1976) 34: 1066-1077.

34. Arnold B, Brinkschmidt T, Casser HR, Gralow I, Irnich D, et al. (2009) [Multimodal pain therapy: principles and indications]. Schmerz 23: 112-120.

35. Klenerman L, Slade PD, Stanley IM, Pennie B, Reilly JP, et al. (1995) The prediction of chronicity in patients with an acute attack of low back pain in a general practice setting. Spine (Phila Pa 1976) 20: 478-484

36. Waddell G, Newton M, Henderson I, Somerville D, Main CJ (1993) A Fear-Avoidance Beliefs Questionnaire (FABQ) and the role of fear-avoidance beliefs in chronic low back pain and disability. Pain 52: 157-168.

37. Ahlund K, Bäck M, Sernert N (2013) Fear-avoidance beliefs and cardiac rehabilitation in patients with first-time myocardial infarction. J Rehabil Med 45: 1028-1033

38. Astfalck RG, O'Sullivan PB, Straker LM, Smith AJ (2010) A detailed characterisation of pain, disability, physical and psychological features of a small group of adolescents with non-specific chronic low back pain. Man Ther 15: 240-247.

39. O'Keeffe M, Purtill H, Kennedy N, O'Sullivan P, Dankaerts W, et al. (2015) Individualised cognitive functional therapy compared with a combined exercise and pain education class for patients with non-specific chronic low back pain: study protocol for a multicentre randomised controlled trial. BMJ Open 5: 007156

40. Burton AK, Waddell G, Tillotson KM, Summerton N (1999) Information and advice to patients with back pain can have a positive effect. A randomized controlled trial of a novel educational booklet in primary care. Spine (Phila $\mathrm{Pa}$ 1976) 24: 2484-2491

41. Somerville S, Hay E, Lewis M, Barber J, van der Windt D, et al. (2008) Content and outcome of usual primary care for back pain: a systematic review. $\mathrm{Br}$ J Gen Pract 58: 790-797. 